Research Article

\title{
Role of pharmaco-epidemiology in psychopharmacology: a study in psychiatric out-patient department of a tertiary care teaching hospital at Dehradun, Uttarakhand
}

\author{
Shaktibala Dutta ${ }^{1}$, Mirza Atif Beg ${ }^{1 *}$, Saubhagya Sindhu ${ }^{1}$, Nand Kishore Singh ${ }^{2}$
}

\begin{abstract}
${ }^{1}$ Department of Pharmacology, Shri Guru Ram Rai Institute of Medical and Health Sciences, Dehradun, Uttarakhand, India, ${ }^{2}$ Department of Psychiatry, Shri Guru Ram Rai Institute of Medical and Health Sciences, Dehradun, Uttarakhand, India
\end{abstract}

Received: 09 May 2014 Accepted: 23 May 2014

*Correspondence to: Dr. Mirza Atif Beg, Email: mabeg1997@gmail.com

C 2014 Dutta SB et al. This
is an open-access article
distributed under the terms
of the Creative Commons
Attribution Non-Commercial
License, which permits
unrestricted non-commercial
use, distribution, and
reproduction in any medium,
provided the original work is
properly cited.

(C) 2014 Dutta SB et al. This is an open-access article distributed under the terms of the Creative Commons Attribution Non-Commercial unrestricted non-commercial use, distribution, and

\begin{abstract}
Background: Prescription auditing studies are a part of drug utilization studies, are beneficial in clinical practice for rational prescribing of drugs and helpful for minimizing the medication errors. They are important tool to promote rational prescribing.

Methods: This was a prospective drug utilization study conducted by the Department of Pharmacology in Psychiatry out-patient department at Shri Guru Ram Rai Institute of Medical and Health Sciences, Dehradun for a period of 6 months. A total of 311 prescriptions were evaluated for prescribing pattern using World Health Organization drug indicators and National Essential Medicine List (NEML) 2011.

Results: A total of 311 prescriptions were evaluated, 157 (50.48\%) were females, and $154(49.52 \%)$ were males, mean age was $37.14 \pm 0.8$ years. Majority of patients were married $207(66.56 \%)$, housewife $116(37.30 \%)$ and belong to middle socioeconomic group $205(65.92 \%)$. A total of 1250 drugs were prescribed, anti-anxiety (anti-A) 379 (30.32\%), anti-depressants (anti-Ds) 348 (27.84\%), anti-psychotics (anti-Ps) 118 (9.44\%), anti-epileptics (anti-Es) 64 (5.12\%), mood stabilizer 20 (1.6\%), anticholinergics 28 (2.24\%) and others 293 (23.44\%). Oral formulations 1247 (99.76\%), 4.02 drugs/prescription, $100 \%$ drugs were prescribed by brand names. $220(17.6 \%)$ fixed dose combinations were prescribed. Most frequently prescribed among anti-A drugs were propranolol 160 (42.22\%) and diazepam 105 (27.70\%), among anti-Ds drugs were amitriptyline $65(18.68 \%)$ and escitalopram 59 (16.95\%) and among anti-Ps risperidone 49 (41.53\%) and olanzapine 38 (32.20\%), respectively. About 51.36\% drugs were prescribed from the NEML 2011. Result has revealed polypharmacy in the practice.

Conclusions: Anti-A drugs were the most commonly prescribed drugs followed by anti-Ds, anti-Ps and anti-Es respectively. Rational prescribing requires further consideration with special reference to polypharmacy and providing feedback to the physicians.
\end{abstract}

Keywords: Pharmaco-epidemiology, Psychopharmacology, Rational prescribing

\section{INTRODUCTION}

Physicians/medical professionals are continuously exposed to newly introduced drugs that are claimed to be safer and more efficacious. Their utilization and consequences on real-life effectiveness and safety in actual clinical practice need continuous study. ${ }^{1}$ Rational drug prescribing is defined as the use of the least number of drugs to obtain the best possible effect in the shortest period and at a reasonable cost. Measurement of drug use in health facilities not only describes drug use patterns and prescribing behavior, but also helps in the identification of factors responsible for the practice of polypharmacy and the problems associated with it. $^{2}$ Drug utilization study has been defined by the World Health Organization (WHO) as "the marketing, distribution, prescription and uses of drugs in a society with special emphasis on the resulting medical and social and economical consequences." 3

Studies on the process of drug utilization focus on the factors related to the prescribing, dispensing, administering, and taking of medication, and its associated events, covering the medical and non-medical determinants of drug utilization, the effects of drug utilization, as well as studies of how drug 
utilization relates to the effects of drug use, beneficial or adverse. The therapeutic practice is expected to be primarily based on evidence provided by premarketing clinical trials, but complementary data from post-marketing period are needed to provide an adequate basis for improving drug therapy. The principle aim of the drug utilization research is to facilitate the rational use of the drugs. Without the knowledge of how the drugs are being prescribed, it is difficult to suggest the measures to improve prescribing habits. ${ }^{3}$ The present study was undertaken to analyze the pattern of drug utilization in patients visiting the out-patient Department (OPD) of psychiatry in a tertiary care teaching hospital at Dehradun.

\section{METHODS}

A prospective cross-sectional, unicentric drug utilization study was conducted in the psychiatry OPD by Department of Pharmacology at Shri Guru Ram Rai Institute of Medical and Health Sciences, Dehradun for a period of 6 months. The present study was conducted on 311 patients who visited the psychiatry OPD during September 2012-February 2013. After obtained approval from the Institutional Ethical Committee, the study was conducted.

Patient-related information (age, sex, and diagnosis) and drug-related information (drugs, dosage form, and route of administration) were recorded on a customized data collection sheet. The prescriptions were analyzed based on WHO drug use indicators and National Essential Medicine List (NEML) 2011.

\section{RESULTS}

During the study period, 311 prescriptions were randomly collected and analyzed. A total of 1250 drugs were prescribed. Majority of the psychiatric illnesses $(47.27 \%)$ were observed in the age group of 31-50 years in both sexes. The mean age was $37.14 \pm 0.8$ years, $157(50.48 \%)$ were females and $154(49.52 \%)$ were males with the male to female of $1: 1.02$. Majority of patients were married 207 (66.56\%), housewife $116(37.30 \%)$, and belonged to middle socio-economic group $205(65.92 \%)$ (Table 1).

In our study, depression (DP) was the most common psychiatric disease encountered 91 (29.26\%), followed by psychotic illness $74(23.79 \%)$, bipolar disorder (BPD) $51(16.40 \%)$, generalized anxiety disorder $32(10.29 \%)$, epilepsy $26(8.36 \%)$ and obsessive compulsive disorder $26(8.36 \%)$. Others include dementia, social phobia, mental retardation and account for the remaining 11 (3.54\%) cases (Figure 1).

Of total 1250 drugs prescribed in our study, anti-anxiety (anti-A) were among the most frequently prescribed drugs $379(30.32 \%)$, followed by anti-depressants (anti-Ds) 348 (27.84\%), anti-psychotics (anti-Ps) 118 (9.44\%),
Table 1: Demographic profile of patients.

\begin{tabular}{|ll|}
\hline Patient parameters & Number (\%) \\
\hline Mean age & $37.14 \pm 0.8$ \\
\hline Age in years & \\
\hline$<18$ & $10(3.22)$ \\
\hline $18-30$ & $106(34.08)$ \\
\hline $31-50$ & $147(47.27)$ \\
\hline $51-70$ & $38(12.21)$ \\
\hline$>70$ & $10(3.22)$ \\
\hline Female:male & $1.02: 1$ \\
\hline Middle:poor SES & $1.93: 1$ \\
\hline Married:unmarried & $2.38: 1$ \\
\hline Non-vegetarian:vegetarian & $1.01: 1$ \\
\hline Occupation & \\
\hline Businessman & $65(20.90)$ \\
\hline Housewife & $116(37.30)$ \\
\hline Farmer/laborer & $27(8.68)$ \\
\hline Teacher/government job & $18(5.79)$ \\
\hline Jobless & $28(9.00)$ \\
\hline Student & $49(15.76)$ \\
\hline Retired & $8(2.57)$ \\
\hline SES: Socio-cconomic stats & \\
\hline
\end{tabular}

SES: Socio-economic status

anti-epileptics (anti-Es) 64 (5.12\%), anti-cholinergics (anti-Cs) 28 (2.24\%), mood stabilizers (MS) 20 (1.6\%) and 293 (23.44\%) drugs were from the others category (Figure 2). Other drugs, which were prescribed included multivitamins and anti-oxidants, non-steroidal anti-inflammatory drugs (paracetamol, diclofenac, and naproxen), proton pump inhibitors (pantoprazole, rabeprazole), anti-emetics (domeperidone), anti-biotics (cefixime, ciprofloxacin), cognition enhancers (donepezil, memantine), anthelminthics (albendazole), anti-histaminics (levocetrizine), and antiamoebics (tinidazole) (Figure 6).

Among anti-A drugs propranolol (PPN) 160 (42.22\%) was frequently prescribed followed by diazepam (DZP) 105 (27.70\%), clonazepam (CZP) 67 (17.68\%) and lorazepam (LZP) 20 (5.28\%) (Figure 3). Amitriptyline (AMT) tricyclic anti-D (TCA) 65 (18.68\%) followed by escitalopram (ECP) (selective serotonin reuptake inhibitors [SSRIs]) $59(16.95 \%)$ were the most commonly prescribed anti-Ds (Figure 4). Risperidone (RPD) (atypical) 49 (41.53\%) was the most common anti-P drug prescribed, followed by olanzapine (OLZP) 38 (32.20\%) and amisulpiride 15 (12.71\%) (Figure 5). Pregabalin, followed by sodium valproate and topiramate were the most commonly prescribed anti-Es. Lithium carbonate and trihexiphenydyl were the most commonly prescribed MS and anti-C drug, respectively (Table 2). Average number of drugs per prescription was 4.02 and $100 \%$ drugs were prescribed by their brand names. About $99.76 \%$ oral formulations, $17.6 \%$ fixed dose combinations (FDCs) and $51.36 \%$ drugs were prescribed from the NEML-2011 (Table 3). 


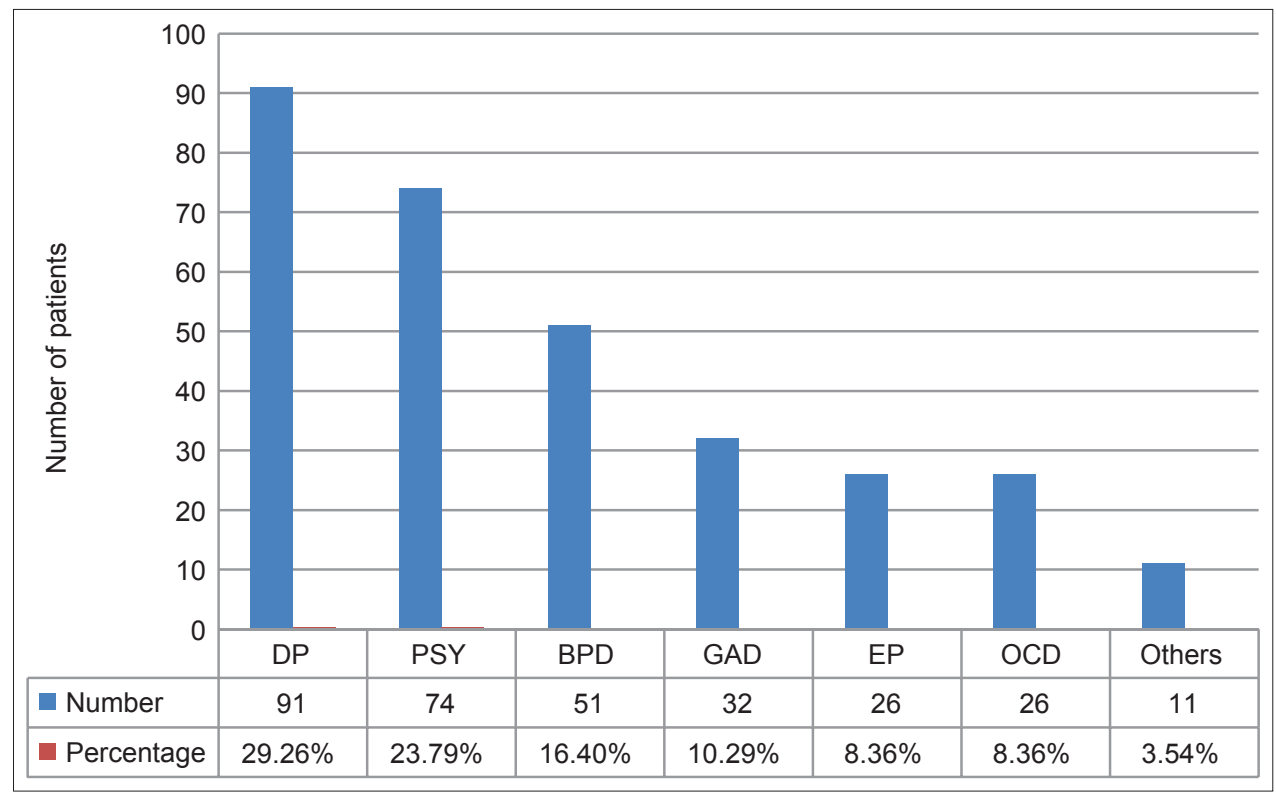

Figure 1: Pattern of psychiatric illness (N=311). DP: Depression, PSY: Psychotic illness, BPD: Bipolar disorder, GAD: Generalized anxiety disorder, EP: Epilepsy, OCD: Obsessive compulsive disorder.

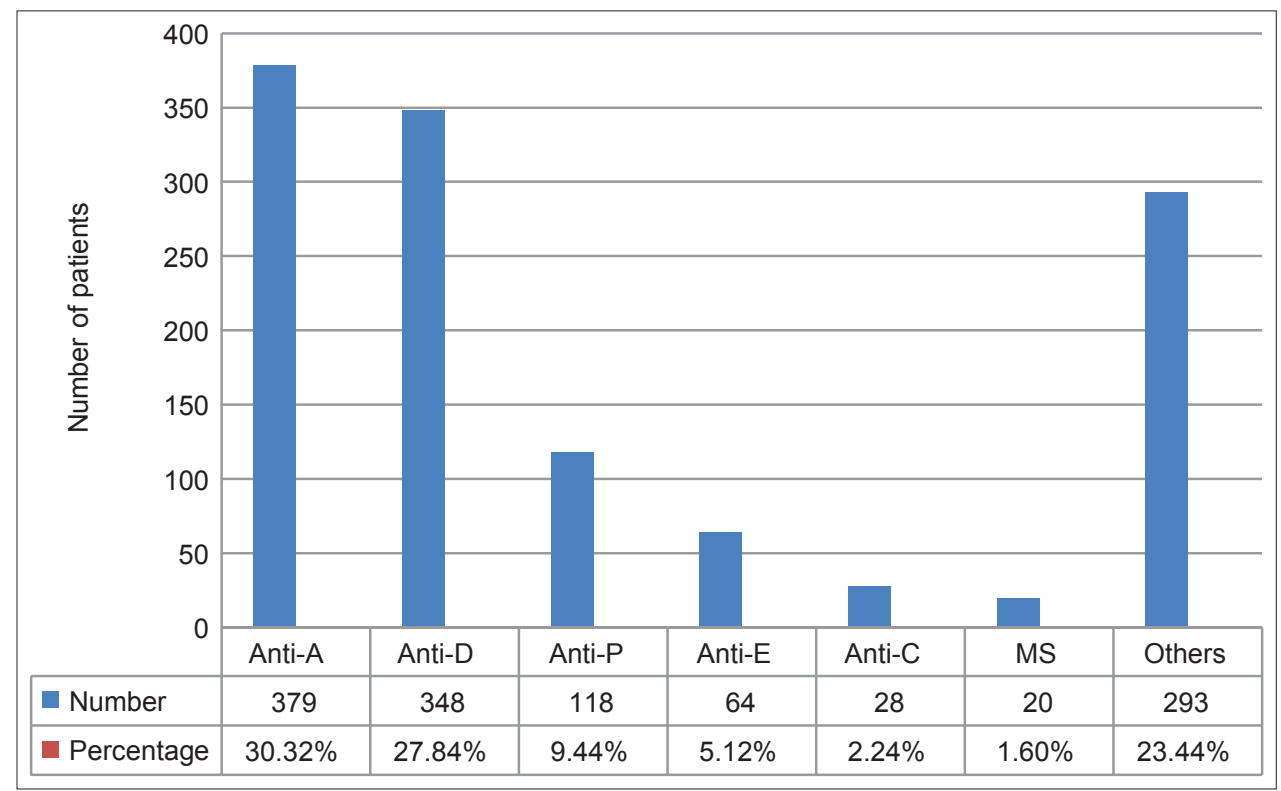

Figure 2: Drug prescribing pattern (N=1250). Anti-A: Anti-anxiety, Anti-D: Anti-depressant, Anti-P: Anti-psychotic, Anti-E: Anti-epileptic, Anti-C: Anti-cholinergic, MS: Mood stabilizer.

Table 2: Most commonly prescribed drugs.

\begin{tabular}{|ll|}
\hline Drug class & Name \\
\hline Anti-anxiety & Propranolol \\
\hline Anti-depressants & Amitryptyline \\
\hline Anti-psychotics & Risperidone \\
\hline Anti-epileptics & Pregabalin \\
\hline Mood stabilizers & Lithium carbonate \\
\hline Anti-cholinergics & Trihexiphenidyl \\
\hline Others & $\begin{array}{l}\text { Multivitamin and } \\
\text { antioxidants }\end{array}$ \\
\hline
\end{tabular}

Table 3: World Health Organization recommended prescribing indicators $(\mathbf{N}=\mathbf{3 1 1})$.

\begin{tabular}{|lc|}
\hline Average number of drugs/prescription & 4.02 \\
\hline $\begin{array}{l}\text { Percentage of the drugs prescribed by } \\
\text { generic name }\end{array}$ & $0 \%$ \\
\hline Percentage of FDC & $17.6 \%$ \\
\hline Percentage of oral formulations & $99.76 \%$ \\
\hline $\begin{array}{l}\text { Percentage of the drugs prescribed from } \\
\text { NLEM } 2011\end{array}$ & $51.36 \%$ \\
\hline
\end{tabular}

FDC: Fixed drug combination, NLEM: National essential medicine list 


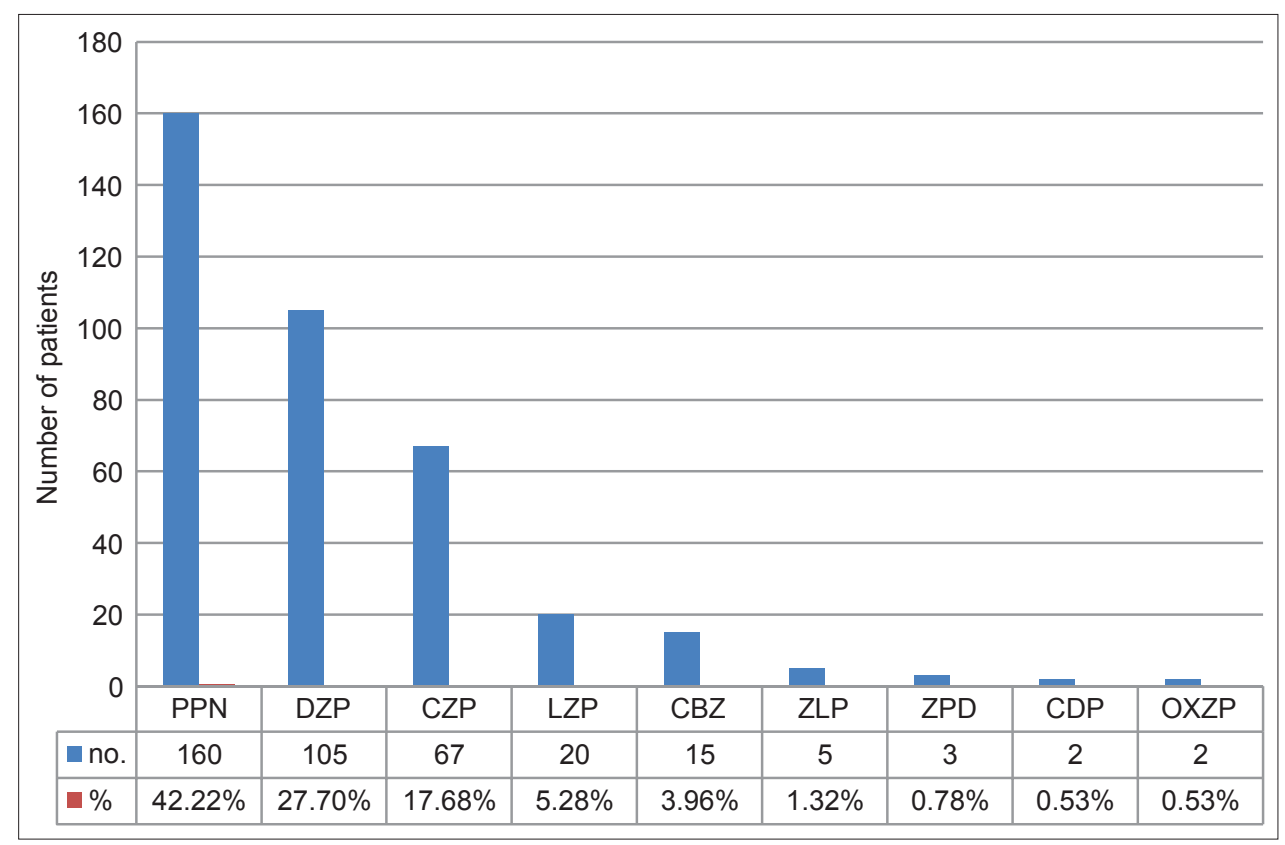

Figure 3: Most commonly prescribed anti-anxiety drugs (N=379). PPN: Propranolol, DZP: Diazepam, CZP: Clonazepam, LZP: Lorazepam, CBZ: Clobazam, ZLP: Zaleplon, ZPD: Zolpedem, CDP: Chlordiazepoxide, OXZP: Oxazepam.

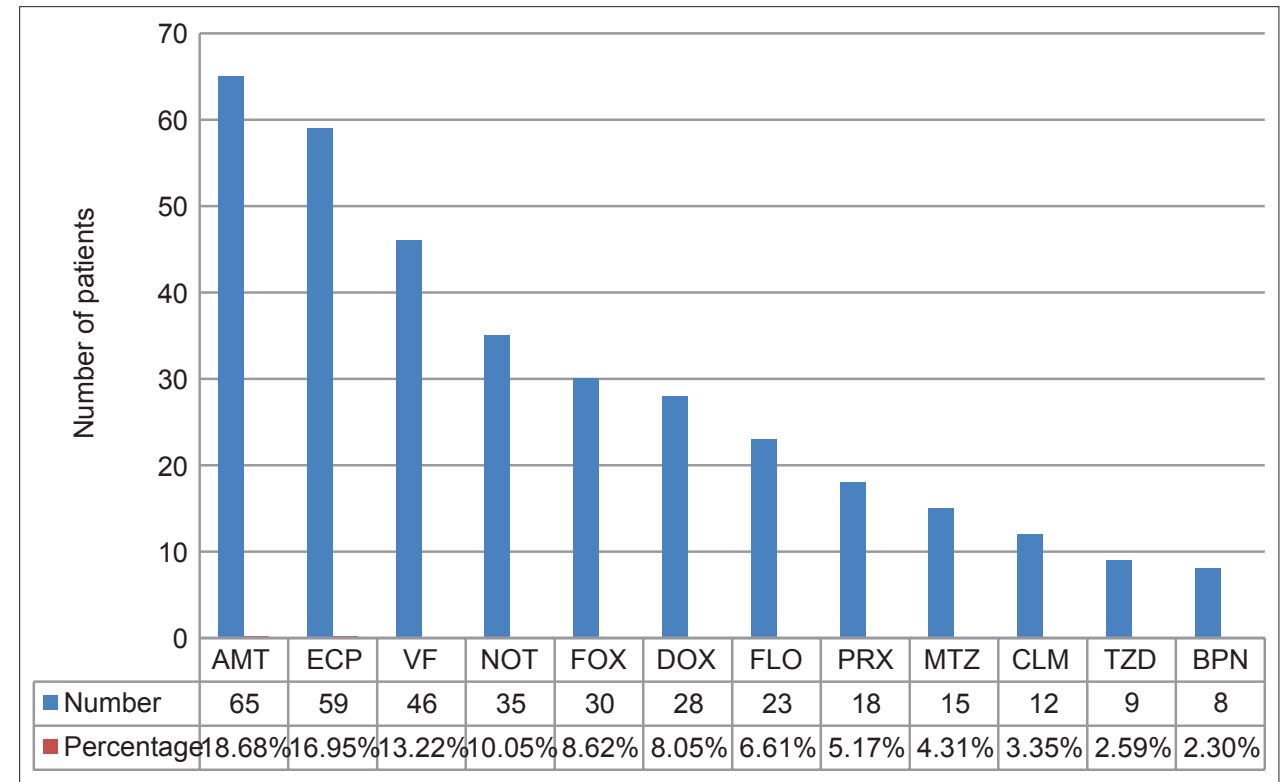

Figure 4: Most commonly prescribed anti-depressant drugs $(\mathrm{N}=348)$. AMT: Amitriptyline, ECP: Escitalopram, VF: Venlafaxine, NOT: Nortriptyline, FOX: Fluoxetine, DOX: Duloxetine, FLO: Fluvoxamine, PRX: Paroxetine, MTZ: Mirtazapine, CLM: Clomipramine, TZD: Trazodone, BPN: Bupropion.

\section{DISCUSSION}

A prescription may be taken as a reflection of the physician's attitude towards the disease and the role of the drug in its treatment providing an insight into the nature of the health care delivery system. Information obtained from frequent medical audits is required to improve prescribing pattern.

Out of the total 311 prescriptions analyzed, male to female ratio was 1:1.02, which is consistent with studies by Grover et al. and Shankar and Roy., ${ }^{4,2}$ Majority of patients were in the age group range of 30-51 years in both sexes, which is similar to studies by Trivedi et al. and Piparva et al. ${ }^{5,6}$ Majority of the patients attending our institution belonged to middle socioeconomic group, which is similar to Dutta et al. ${ }^{7}$

In our study, DP was the most common psychiatric illness, followed by psychosis and BPD, which is similar to study by Piparva et al. ${ }^{6}$ In another study by Grover et al. anxiety disorder formed the most common diagnostic group, followed by DP. ${ }^{8}$ 


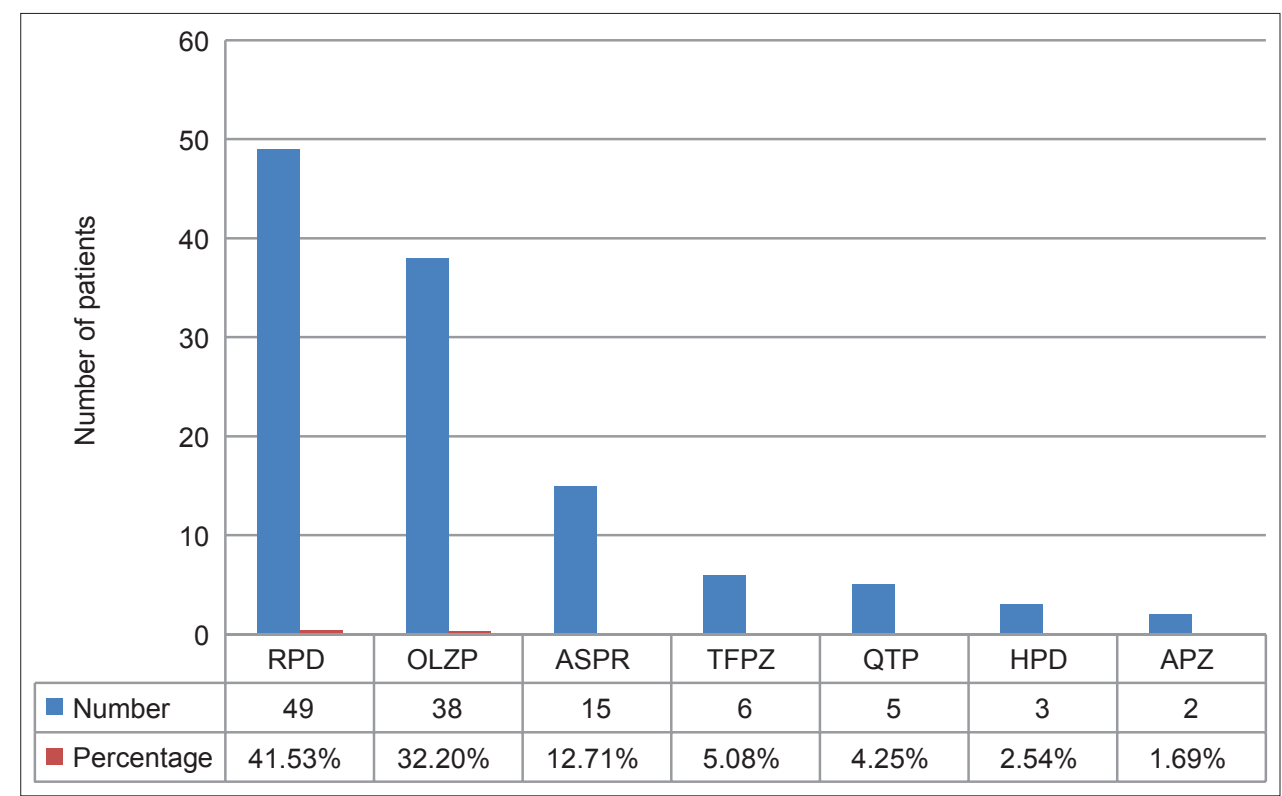

Figure 5: Most commonly prescribed anti-psychotic drugs (N=118). RPD: Risperidone, OLZP: Olanzapine, ASPR: Amisulpride, TFPZ: Trifluperazine, QTP: Quetiapine, HPD: Haloperidol, APZ: Aripiprazole.

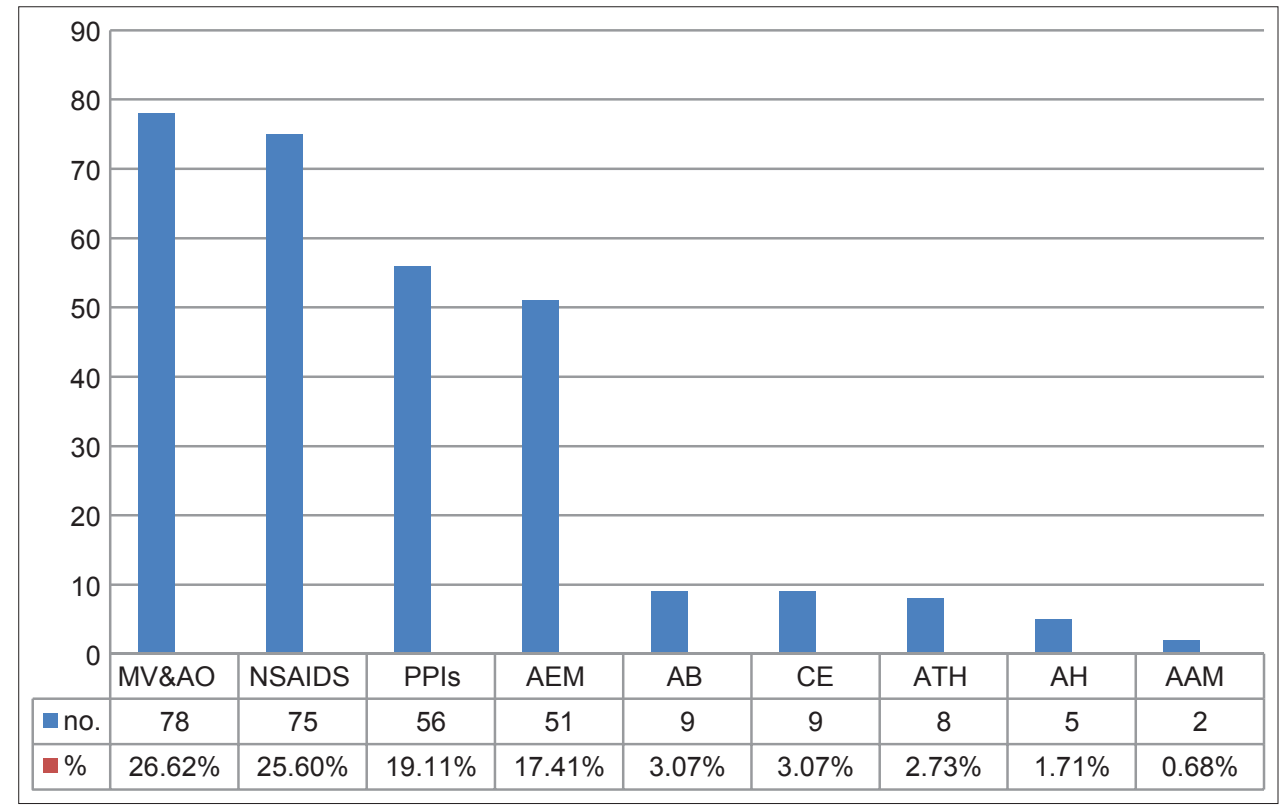

Figure 6: Drugs included in others category (N=293). MV and AO: Multivitamin and antioxidants, AEM: Anti-emetics, AB: Antibiotics, CE: Cognition enhancers, ATH: Anthelminthics, AH: Anti-histaminics, AAM: Anti-amoebics.

Anti-A drugs are remarkably useful and efficacious in a wide range of conditions for short-term or intermittent use. Out of total 1250 drugs prescribed in our study anti-A drugs constituted the most commonly prescribed drug group. The results are similar to previous studies by Dutta et al. where anti-A drugs were among the most commonly prescribed drugs. ${ }^{7}$ PPN was the most common anti-A drug prescribed in our study, followed by DZP, CZP and LZP. In previous studies by Grover et al. and Trivedi et al. CZP was the most commonly prescribed anti-A agent prescribed. ${ }^{8,5}$ Our study reconfirms the fact that anxiety symptoms are co-morbid with DP and require medication, which is similar to study by Trivedi et al. ${ }^{5}$

Anti-D constituted the second most frequently prescribed group. TCA and SSRI were the most frequently prescribed anti-D drugs. Among the TCAs AMT and SSRIs ECP were the most commonly prescribed agents. These findings are in consonance with other studies by Piparva et al. and Grover et al. ${ }^{6,8}$ In another study by Trivedi et al. duloxetine was the most frequently prescribed antidepressant, followed by ECP. ${ }^{5}$ SSRI are generally free of sedative effects and safer 
at higher doses. Better tolerability, combined with their mild adverse effects, accounts for their popularity as the most widely prescribed anti-Ds along with TCAs. ${ }^{2,9}$

Among the anti-Ps atypical agents such as RPD, OLZP and amisulpiride were most commonly prescribed. The results are similar to previous studies by Piparva et al., Sahana et al. and Grover et al. ${ }^{6,10,8}$ Atypical anti-Ps are now rated as first line agents since they have low propensity to cause extra-pyramidal side effects, efficacy against refractory cases, better tolerance, low relapse rate, and safer adverse effect profile. ${ }^{11}$ Lithium carbonate and trihexyphenidyl was the most commonly prescribed MS and anti-C drug respectively, which is in concordance with the study by Piparva et al. ${ }^{6}$ Although frequency of prescribing atypical anti-P was higher in our study, yet the anti-C agents were prescribed to the patients. Similar observation was observed in a study by Ren et al. where when anti-C agents were used concomitantly with atypical anti-Ps, patients tend to stay on target drug significantly longer than those who did not use any anticholinergic agents. ${ }^{12}$

The average number of drugs per prescription is an important index of the scope for review and educational intervention in prescribing practices. The average number of drugs per prescription in our study is 4.02, higher compared to studies by Shankar and Roy, Piparva et al. and Dutta et al.,2,6,7 Although irrational polypharmacy occurs too frequently but in many instances it is necessary to manage the patient with multiple medications and that makes rational polypharmacy. ${ }^{13}$ Clinicians may use polypharmacy in patients as combination therapy for symptom relief, while using lower doses of drugs with differing side-effects profiles. Concerns with polypharmacy include the possibility of cumulative toxicity and increased vulnerability to adverse events as well as adherence issues, which emerge with increasing regimen complexity. ${ }^{14}$ About $17.6 \%$ FDCs were prescribed in our study, which is higher than the previous study by Shankar and Roy and Dutta et al., $51.36 \%$ drugs prescribed were from the NEML-2011, which higher than the study by Shankar and Roy. ${ }^{2}$ In our study, $99.76 \%$ oral formulations were prescribed, which is not comparable to previous study by Dutta et al. ${ }^{7}$ One hundred percentage drugs were prescribed by their brand names, which is comparable to previous study by Sahana et al. and greater than another study by Shankar and Roy. ${ }^{2,10}$ This is not in accordance with the WHO guidelines as rational prescribing requires generic prescription.

\section{CONCLUSION}

Studying and analyzing the prescription patterns seeks to monitor, evaluate and help the physicians in understanding how the available drugs can be best put to use practically. They suggest, if necessary, modifications in prescribing patterns so as to make medical care rational and our study was a step in that direction. Polypharmacy was seen in our study that requires reconsideration. Polypharmacy increases the risk of drug interactions and thereby morbidity as well as mortality.

\section{Limitations}

Our study has several limitations. We might have focused only on the first prescription, and this necessarily does not reflect the true clinical situation. Depending on the response in many patients, further medications may have been added or tapered off. We did not document the dose and dosing schedule of the treatment given. We also did not evaluate factors such as treatment adherence, availability of supervision, concerns of the patients about side-effects, and adherence to treatment guidelines, while prescribing.

Funding: No funding sources

Conflict of interest: None declared

Ethical approval: The study was approved by the Institutional Ethics Committee

\section{REFERENCES}

1. Meyer JM. Pharmacotherapy of psychosis and mania. In: Brunton LL, Chabner BA, Knollmann BC, editors. Goodman and Gillman's the Pharmacological Basis of Therapeutics. 12th Edition. New York: McGraw-Hill; 2011: 417-55.

2. Shankar PR, Roy S. Patterns of prescription and drug use in a psychiatry out-patient department in a teaching hospital in Western Nepal. Internet J Pharmacol. 2002;1(2):1-6.

3. World Health Organization. Introduction to Drug Utilization Research. Geneva: World Health Organization; 2003: 6-48.

4. Grover S, Avasth A, Kalita K, Dalal PK, Rao GP, Chadda RK, et al. IPS multicentric study: antidepressant prescription patterns. Indian J Psychiatry. 2013;55(1):41-5.

5. Trivedi JK, Dhyani M, Sareen H, Yadav VS, Rai SB. Antidepressant drug prescription pattern for depression at a tertiary health care centre of Northern India. Med Pract Rev. 2010;1(2):16-8.

6. Piparva KG, Parmar DM, Singh AP, Gajera MV, Trivedi HR. Drug utilization study of psychotropic drugs in outdoor patients in a teaching hospital. Indian J Psychol Med. 2011;33(1):54-8.

7. Dutta S, Beg MA, Kaul V, Dutta SH, Dhasmana DC. Psychotropic drug utilization study in psychiatric OPD of a tertiary care teaching hospital in Dehradun, Uttarakhand. J Adv Res Biol Sci. 2013;5(4):386-91.

8. Grover S, Kumar V, Avasthi A, Kulhara P. An audit of first prescription of new patients attending a psychiatry walk-inclinic in north India. Indian J Pharmacol. 2012;44(3):319-25.

9. Battista CD. Antidepressant agents. In: Katzung BG, Masters SB, Trevor AJ, editors. Basic and Clinical Pharmacology. 11th Edition. New York: McGraw Hill; 2012: 509-30.

10. Sahana DA, Keshava P, Rajeshwari S, Ullal SD, Rathnakar UP, Jaykumar JS. Pattern of psychotropic drug usage in psychiatric illnesses among elderly. J Med Dev Ctries. 2010;2(1):3-10.

11. Dhasmana DC, Rawat Y, Mishra KC. What is so atypical about atypical antipsychotic? Indian J Pharmacol. 2003;35:322-4.

12. Ren XS, Huang YH, Lee AF, Miller DR, Qian S, Kazis L. Adjunctive use of atypical antipsychotics and anticholinergic drugs among patients with schizophrenia. J Clin Pharm Ther. 2005;30(1):65-71. 
13. Stahl SM. Antipsychotic polypharmacy: never say never, but never say always. Acta Psychiatr Scand. 2012;125(5):349-51.

14. Trumic E, Pranjic N, Begic L, Becic F, Asceric M. Idiosyncratic adverse reactions of most frequent drug combinations longterm use among hospitalized patients with polypharmacy. Med Arh. 2012;66(4):243-8. doi: 10.5455/2319-2003.ijbcp20140813

Cite this article as: Dutta SB, Beg MA, Sindhu S,

Singh NK. Role of pharmaco-epidemiology in

psychopharmacology: a study in psychiatric out-patient department of a tertiary care teaching hospital at Dehradun, Uttarakhand. Int J Basic Clin Pharmacol 2014;3:637-43. 